\title{
ADSORPTION OF STRONTIUM IONS FROM WATER ON MODIFIED ACTIVATED CARBONS
}

\author{
Mihai Ciobanu*, Victor Botan, Tudor Lupascu, Tatiana Mitina, Maria Rusu \\ Institute of Chemistry of Academy of Sciences of Moldova, 3, Academiei str., Chisinau MD-2028, Republic of Moldova \\ *e-mail:mihai_ciobanu2002@yahoo.co.uk
}

\begin{abstract}
Adsorption of strontium ions from aqueous solutions on active carbons CAN-7 and oxidized CAN-8 has been studied. It has been found that allure of the adsorption isotherms for both studied active carbons are practically identical. Studies have shown that the adsorption isotherms for strontium ions from aqueous solutions are well described by the Langmuir and Dubinin-Radushkevich equations, respectively. The surface heterogeneity of activated carbons CAN-7 and oxidized CAN-8 has been assessed by using Freundlich equation.
\end{abstract}

Keywords: adsorption, strontium ions, modified activated carbon.

Received: April 2016/ Revised final: November 2016/ Accepted: November 2016

\section{Introduction}

Moldovan ground waters usually contain various pollutants, and most frequently encountered are hydrogen sulphide also ions of iron, manganese, strontium and ammonium (ammonia). When strontium ions are present in potable water in concentrations higher than maximum allowable, they slow down the growth in height of children and replace the calcium ions from bone, causing various diseases. In some wells the content of strontium ions may reach $48 \mathrm{mg} / \mathrm{L}$, a value that exceeds the maximum allowable adopted in European countries $(5 \mathrm{mg} / \mathrm{L})$ [1] and in Russia (7 mg/L, [2]). Thus, the problem of removing the strontium ions in ground water becomes very important.

There are a series of publications devoted to the study of the processes of strontium ions adsorption from aqueous solutions on different carbonaceous adsorbents [3-5]. In these works, the processes of adsorption were studied at different temperatures as a function of $\mathrm{pH}$ and contact time. A series of isotherms of adsorption of strontium ions from aqueous solutions on activated carbons obtained from nuts (pecan) shells have been presented [5], which show not only the variation of the maximum values of absorbance as a function of $\mathrm{pH}$, but also the presence of jump, followed by a significant increase in adsorption. It is worth mentioning here the recently presented results [6], namely the mass spectrum of activated carbon obtained by chemical activation with ortho-phosphoric acid from the shells of pecan nuts is conclusive for the presence of various types of functional groups on the surface of carbonaceous adsorbent.

This paper aims to study the process of adsorption of strontium ions from water on activated carbons obtained from vegetable by-products that are subsequently modified in order to assess the possibility of removing the strontium ions from the ground water.

\section{Materials and methods}

\section{Experimental procedure}

Activated carbon CAN-7 was obtained from Greek walnut shells that are waste of the food industry. The technology of obtaining this adsorbent includes walnut shells impregnation with ortho-phosphoric acid with further heating thereof up to $80^{\circ} \mathrm{C}$ and then activation at $460^{\circ} \mathrm{C}$. Activated carbon CAN-8 was obtained from nut shells by physico-chemical method. Activation was carried out with water vapour at a temperature of $960^{\circ} \mathrm{C}$. The obtained activated carbon was modified via oxidation with $20 \%$ nitric acid at a temperature of $80^{\circ} \mathrm{C}$. Quality indices of the initial activated carbon CAN-8 were published by us earlier [7].

\section{Measurements}

Structure parameters of activated carbons CAN-7 and oxidized CAN-8 (CAN-8ox) were determined from adsorption-desorption isotherms of nitrogen measured at 1MP Autosorb facility.

The Fourier Transform Infrared spectroscopic (FTIR) analysis of activated carbon samples was performed using the Fourier Transform Infrared Spectrometer (Perkin Elmer FTIR, Spectrum 100, USA). The IR spectra were recorded in the wave number range of $4000-400 \mathrm{~cm}^{-1}$. Prior to the FTIR analysis the samples were dried and the dilutions in $\mathrm{KBr}$ have been used $(0.15 \mathrm{wt} \%)$ [8].

Adsorption isotherms were determined in static conditions at different initial concentrations of strontium ions in solution and at the same mass of activated carbon, at temperature of $20^{\circ} \mathrm{C}$. The initial concentration of $\operatorname{Sr}\left(\mathrm{NO}_{3}\right)_{2}$ in model solution was $100 \mathrm{mg} / \mathrm{L}, \mathrm{pH}=6.2$. The fraction of activated carbons used in the study was $0.8-1.0 \mathrm{~mm}$. The process of strontium ions adsorption on activated carbon has been studied also on real water (Calarasi, Republic of Moldova), containing in addition to the $\mathrm{Sr}^{2+}$ ions $(9.96 \mathrm{mg} / \mathrm{L})$, also $\mathrm{Ca}^{2+}(37 \mathrm{mg} / \mathrm{L})$ and $\mathrm{Mg}^{2+}(16 \mathrm{mg} / \mathrm{L})$ ions, and pollutants that are often encountered in deep waters. The equilibrium concentrations of strontium ions were determined on spectrophotometer AAS-1. 


\section{Results and discussion}

Structure parameters, the specific surface and pore volume of the activated carbons used in the present study, are presented in Table 1. According to presented data, activated carbon CAN-7 has a relatively high proportion both of small pores (micropores) and larger sized pores (mesopores).

Adsorption isotherm of strontium ions on the activated carbon CAN-7 is shown in Figure 1. Adsorption isotherm presents the specific jump registered in the previous studies [5]. The obtained adsorption isotherm is of the type VI, according to the classification proposed by Brunauer et al. [9]. Such type of adsorption isotherms is not often encountered in literature. Of course, the description of this isotherm by the known patterns can present some difficulties because of the complicated processes occurring at active carbon-solution interface. Here, as a confirmation, the data come from mass spectrometric measurements of activated carbon obtained from the nut shells (pecan) [6], from which carbonyl, carboxylic and phenol groups, aromatic bridges, as well as protonated aromatic carbon and aliphatic carbon are distinguished on the surface of the studied adsorbent.

Adsorption isotherm of strontium ions on the activated carbon CAN-7 in coordinates of Freundlich equation is shown in Figure 2. Presented data (Figure 2) attest a more pronounced deviation of the points from a line at relatively low equilibrium concentrations ( $\mathrm{R}=9.1)$, which obstruct in some degree the precise determination of $n$ index, characterizing the heterogeneity of surface of active carbon CAN-7. Nevertheless, $n$ index has been calculated, being equal to 0.65 .

Table 1

Structure parameters of activated carbons CAN-7 and oxidized CAN-8ox.

\begin{tabular}{cccccccccccc}
\hline \multirow{2}{*}{ Sample } & \multicolumn{2}{c}{$W_{01}$} & $W_{02}$ & $E_{01}$ & $E_{02}$ & $X_{01}$ & $X_{02}$ & $V S$ & $V_{\text {meso }}$ & $S_{\text {meso }}$ & $S_{s p}$ \\
\cline { 2 - 11 } & \multicolumn{2}{c}{$\mathrm{cm}^{3} / g$} & \multicolumn{2}{c}{$\mathrm{kJ} / \mathrm{mol}$} & & $\mathrm{nm}$ & \multicolumn{2}{c}{$\mathrm{cm}^{3} / g$} & $\mathrm{~m}^{2} / g$ \\
\hline CAN-7 & 0.24 & 0.16 & 15.72 & 6.49 & 0.64 & 1.54 & 0.64 & 0.24 & 210 & 725 \\
CAN-8ox & 0.17 & 0.06 & 25.08 & 9.09 & 0.40 & 1.10 & 0.42 & 0.19 & 90 & 650 \\
\hline
\end{tabular}

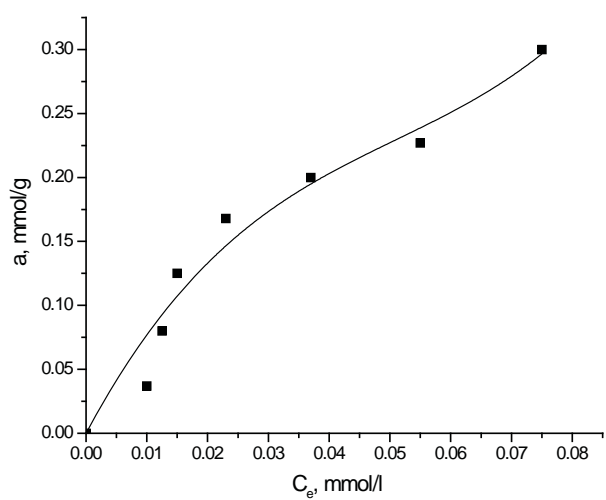

Figure 1. Adsorption isotherm of strontium ions on the activated carbon CAN-7.

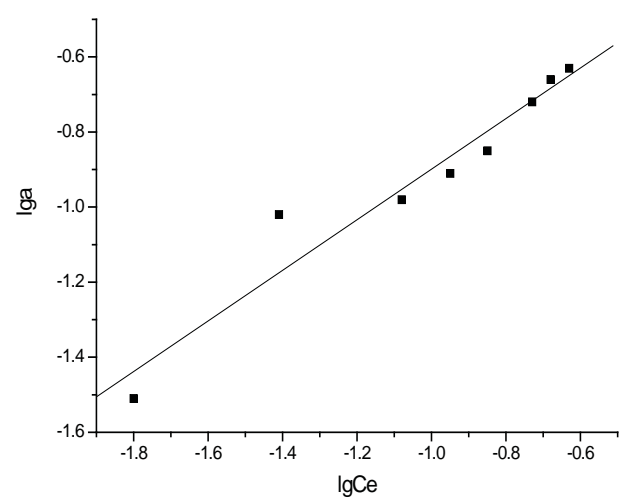

Figure 2. Adsorption isotherm of strontium ions on activated carbon CAN-7 in coordinates of Freundlich equation.

The adsorption isotherm of strontium ions on active carbon CAN-7 in coordinates of Langmuir equation is shown in Figure 3. The data presented in Figure 3 show that the process of adsorption of strontium ions can take place in active centres, even if the points on the isotherm do not stand strictly on straight line, allowing us to conclude that the isotherm depicted in Figure 1 is of Langmuir type.

Figure 4 illustrates the adsorption isotherm for strontium ions on active carbon CAN-7, in coordinates of the Dubinin-Serpinschi-1 (DS-1) equation [10]. From Figure 4 it is evident that adsorption of strontium ions occurs not only in the centres of adsorption, thereby DS-1 equation does not adequately describe the process.

The obtained results allow us to assume that adsorption of the strontium ions from aqueous solutions occurs in the centres of activated carbon $\mathrm{CAN}-7$, both due to ion exchange and other interactions. The mechanism of $\mathrm{Cu}^{2+}$ ions interaction with the oxidized surface of the activated carbon has been schematically represented [11]:

$$
\begin{aligned}
& >\mathrm{C}-\mathrm{H}+\mathrm{Cu}^{2+} \rightarrow>\mathrm{C}-\mathrm{H} \cdots \mathrm{Cu}^{2+}(\text { dipole-dipole interaction }) \\
& >\mathrm{C}-\mathrm{COOH}+\mathrm{Cu}^{2+} \rightarrow>\mathrm{C}-\mathrm{COOCu}{ }^{+}+\mathrm{H}^{+}
\end{aligned}
$$$$
\text { Scheme } 1
$$

Scheme 2 
The same mechanism could be attributed to the adsorption of strontium ions on activated carbon CAN-7. Adsorption and diffusion processes of strontium ions in the sorbent's micropores are discussed by Qadeer et al. [12], being schematically represented in Scheme 3. Scheme 4 represents the adsorbed and diffused strontium in microporous structure of carbonaceous adsorbent $(\mathrm{X})[13]$.

$$
\begin{aligned}
& \mathrm{Sr}^{2+}+\mathrm{H}_{2} \mathrm{O}=\mathrm{Sr}(\mathrm{OH})^{+}+\mathrm{H}^{+} \\
& \mathrm{Sr}(\mathrm{OH})^{+}+\mathrm{X}=\mathrm{Sr}(\mathrm{OH}) \mathrm{X}
\end{aligned}
$$$$
\text { Scheme } 3
$$

Scheme 4

Sveshnikova et al. specified that $\mathrm{Rb}^{+}$and $\mathrm{Cs}^{+}$ions adsorbed on the activated carbon, which was obtained by the treatment with orthophosphoric acid, do not desorb after the hydrochloric acid treatment [14]. This is an indication on the formation of stable chemical compounds between the mentioned ions and functional groups from the adsorbent's surface, obtained after treatment of activated carbon with orthophosphoric acid.

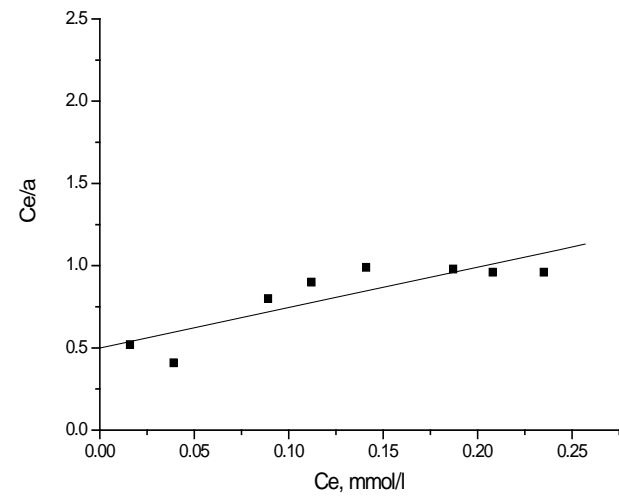

Figure 3. Adsorption isotherm of strontium ions on active carbon CAN-7, in coordinates of Langmuir equation.

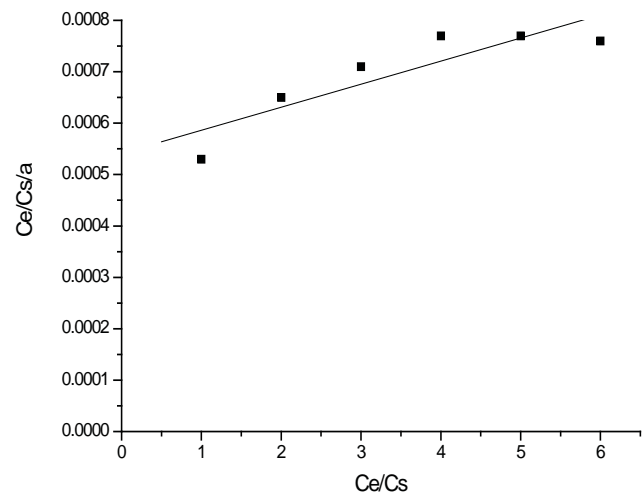

Figure 4. Adsorption isotherm of strontium ions on active carbon $\mathrm{CAN}-7$, in coordinates of DS-1 equation.

Figure 5 presents the FTIR spectra of the initial active carbon CAN-7 and of the sample of active carbon with adsorbed strontium ions CAN-7-Sr. The absorption band at $1175 \mathrm{~cm}^{-1}$ in the FTIR spectrum of the initial active carbon CAN-7 suggests the presence of the phosphates and polyphosphates $(\mathrm{P}=\mathrm{O}$ and $\mathrm{C}-\mathrm{O}-\mathrm{P}$ groups) on its surface.

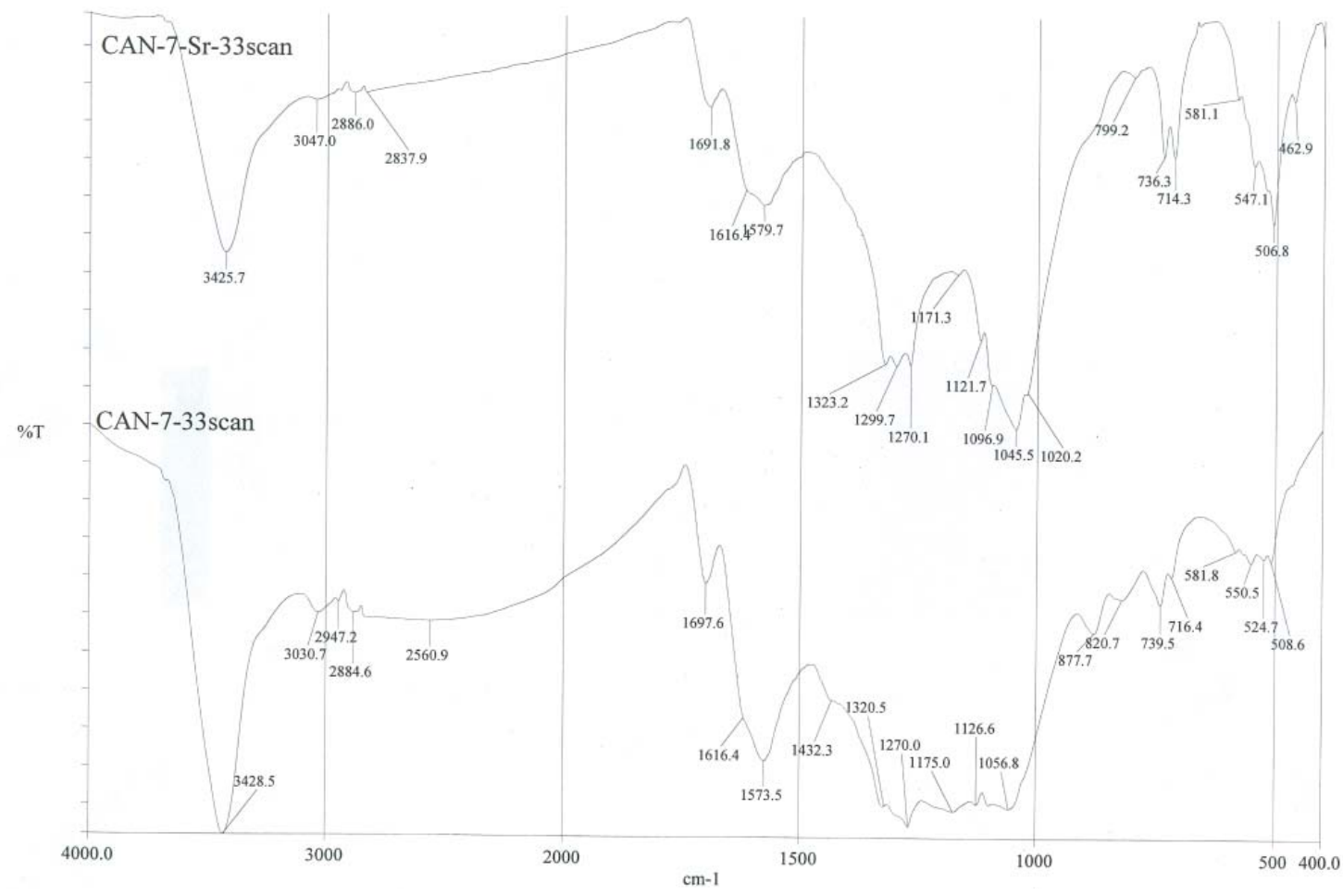

Figure 5. FTIR spectra of initial sample (CAN-7) and sample with adsorbed strontium ions (CAN-7-Sr). 
The FTIR spectra of the initial CAN-8ox active carbon and the sample of active carbon with adsorbed strontium ions CAN-8ox- $\mathrm{Sr}^{2+}$ are shown in Figure 6. According to the data provided by Figure 6, we find that the oscillation band of $\mathrm{C}=\mathrm{O}$ groups from $-\mathrm{COOH}\left(1733.4 \mathrm{~cm}^{-1}\right)$ in $\mathrm{CAN}-8 \mathrm{ox}$ disappear or is significantly diminished after sorption of strontium ions, but in the spectrum become stronger the bands corresponding to symmetrical $\left(1384.6 \mathrm{~cm}^{-1}\right)$ and asymmetric $\left(1570.5 \mathrm{~cm}^{-1}\right)$ oscillations of carboxyl ions, by analogy with the data in the published works [15]. The oscillation band of the carboxylic groups in the FTIR spectrum of CAN-8ox-Sr ${ }^{2+}$ sample moves toward region of lower frequencies (from $1733.4 \mathrm{~cm}^{-1}$ to $1712.7 \mathrm{~cm}^{-1}$ ), which proves the ionization of carboxylic groups.

It should be noted, that cationic exchange capacity of active carbon obtained by activation with orthophosphoric acid is similar to that of oxidized active carbon containing acid functional groups (carboxylic, lactonic, phenolic) [16]. In contrast to the active carbon oxidized with $\mathrm{H}_{2} \mathrm{O}_{2}, \mathrm{HNO}_{3}, \mathrm{O}_{3}, \mathrm{O}_{2}$ and air, the active carbon modified with orthophosphoric acid does not require an additional step of oxidation, for rendering the ion exchange properties.

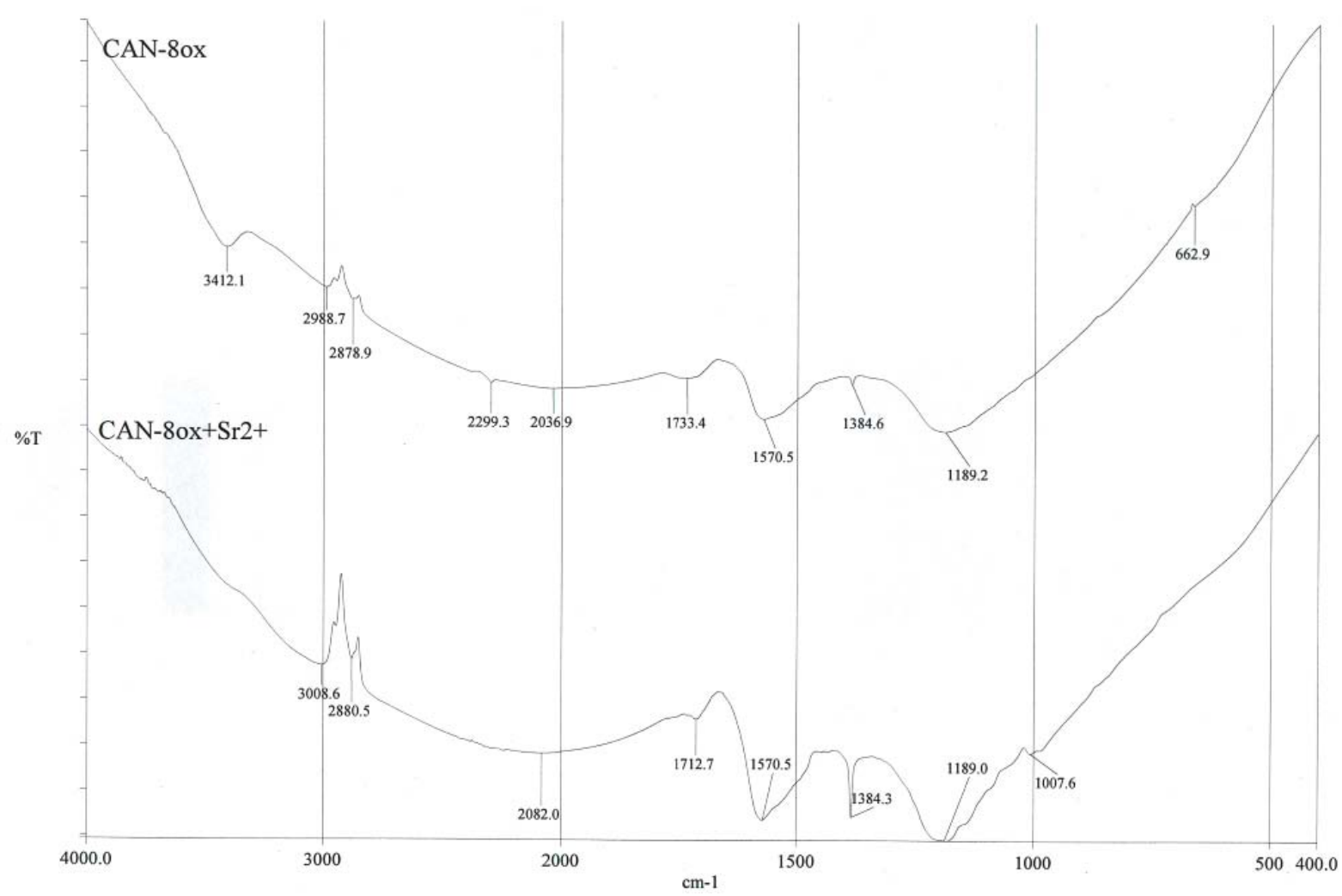

Figure 6. FTIR spectra of initial active carbon (CAN-80x) and of the sample with adsorbed strontium ions $\left(\mathrm{CAN}-80 \mathrm{x}+\mathrm{Sr}^{2+}\right)$.

It was found that the surface of activated carbon, obtained by treating the starting material with orthophosphoric acid, is negatively charged in the range of $1.5-11.0 \mathrm{pH}$ values, as a result of dissociation of functional groups that are present on the surface, according to the equation [15]:

$$
\mathrm{QH}=\mathrm{Q}^{-}+\mathrm{H}^{+}
$$

Thus, the cation exchange capacity of the obtained activated carbon in the range of studied $\mathrm{pH}$ values was higher than that of activated carbon produced from the same raw material and subsequently oxidized. The same authors [17] reported on the formation of the complexes of composition $1: 2\left(\mathrm{Q}_{\mathrm{i}}\right)_{2} \mathrm{Cu}$, as a result of sorption of the $\mathrm{Cu}^{2+}$ ions on the surface of the activated carbon obtained by treatment with orthophosphoric acid. It is mentioned, that phosphate groups on the surface of the adsorbent bind $90 \%$ of all amount of adsorbed $\mathrm{Cu}^{2+}$ ions.

Perhaps in the case of adsorption of $\mathrm{Sr}^{2+}$ ions from aqueous solutions on CAN-7 active carbon, the adsorption process occurs due to the dipole-dipole interaction [10], but also due to the ion exchange. This explains the shape of the isotherm (Figure 1) at very low equilibrium concentrations and the influence of $\mathrm{pH}$ on the adsorption process described in literature [5]. 
Comparison of the values of adsorption of strontium ions on CAN-8ox and CAN-7 (Figure 7), allowed us to establish a big difference in the adsorption capacity of these adsorbents, namely CAN-7 active carbon has a higher adsorption capacity than CAN-8ox activated carbon.

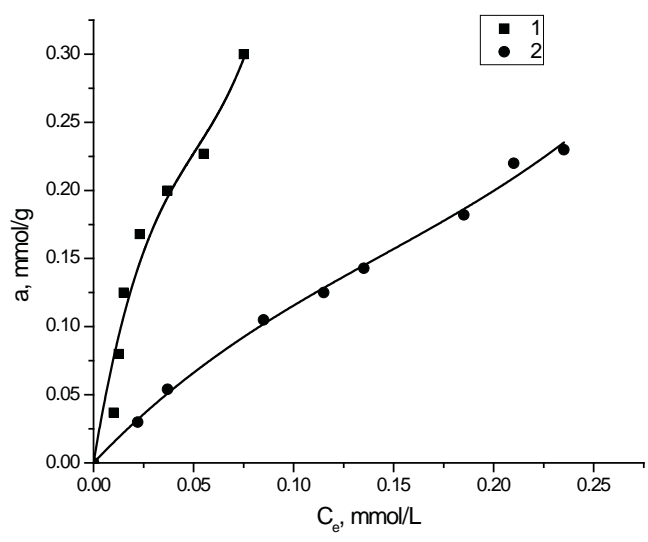

Figure 7. Adsorption isotherms of strontium ions on active carbons: (1) CAN-7; (2) CAN-80x.

The adsorption isotherm of strontium ions from aqueous solutions on CAN-8ox activated carbon is shown in Figure 8, in the linear coordinates of Langmuir equation. According to Figure 8, a great deviation of experimental points from a straight line $(\mathrm{R}=0.66)$ has been attested showing that the adsorption of strontium ions on both CAN-8ox and CAN-7 active carbons takes place not only in the active centres.

The adsorption isotherm of strontium ions from aqueous solution on CAN-8ox active carbon is depicted in Figure 9, in coordinates of DS-1 equation. From the presented data one can conclude that even if DS-1 equation roughly describes the adsorption isotherm for strontium ions on CAN-8ox active carbon, the experimental data points do not sit well on a straight line in the coordinates of DS-1 linear equation $(\mathrm{R}=0.67)$.

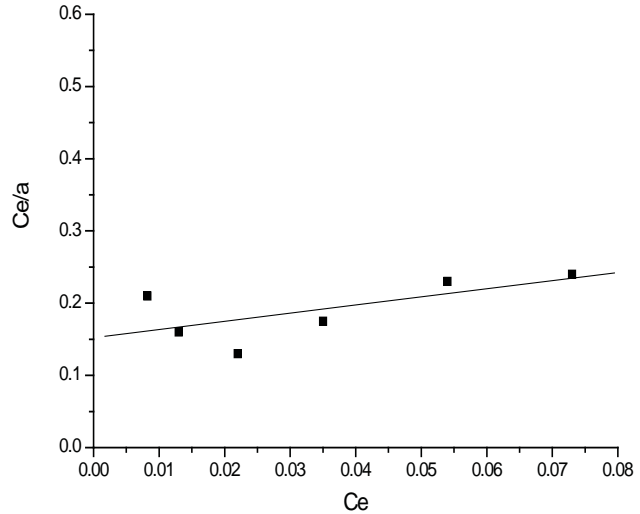

Figure 8. Adsorption isotherm of strontium ions on active carbon CAN-80x, in coordinates of Langmuir equation.

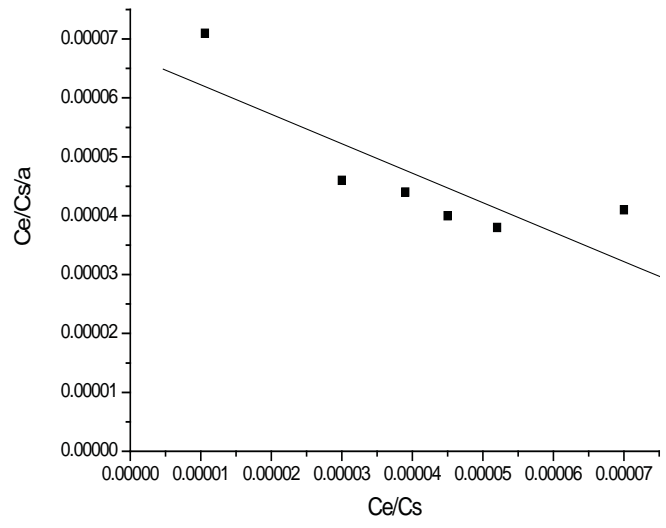

Figure 9. Adsorption isotherm of strontium ions carbon CAN-8ox, in coordinates of DS-1 equation.

Figure 10 illustrates the adsorption isotherm of strontium ions from aqueous solutions on activated carbon CAN-8ox in coordinates of Freundlich equation. From the presented data some variation of data points from a straight line is noticed. The index $n$ value is 0.86 .

According to the literature data, the heterogeneity of adsorbent surface enhances with the decrease of the value of adsorbent surface $n$ index in Freundlich equation [18]. Comparison of the $n$ index values obtained for active carbon CAN-7 containing the adsorbed strontium ions (Figure 2) with the data presented in Figure 10, offers a conclusive evidence on the higher surface heterogeneity of CAN-7, than that of CAN-8ox activated carbon. This can be explained 
by the appearance of some new groups, such as $\mathrm{P}=\mathrm{O}$ and $\mathrm{C}-\mathrm{O}-\mathrm{P}$, characteristic for phosphates and polyphosphates, on the surface of activated carbon CAN-7 obtained by treatment with orthophosphoric acid that increase the heterogeneity of the surface of CAN-7 adsorbent.

Figure 11 presents the adsorption isotherm of strontium ions from aqueous solutions on CAN-7 activated carbon in coordinates of Dubinin-Radushkevich equation (e-Polanyi potential) Eq.(1):

$$
e=R T \ln \left(1+\frac{1}{C e}\right)
$$

where $e$ is Polanyi potential;

$R$ - gas constant;

$T$ - temperature;

$\mathrm{Ce}$ - equilibrium concentration of strontium ions in solution.

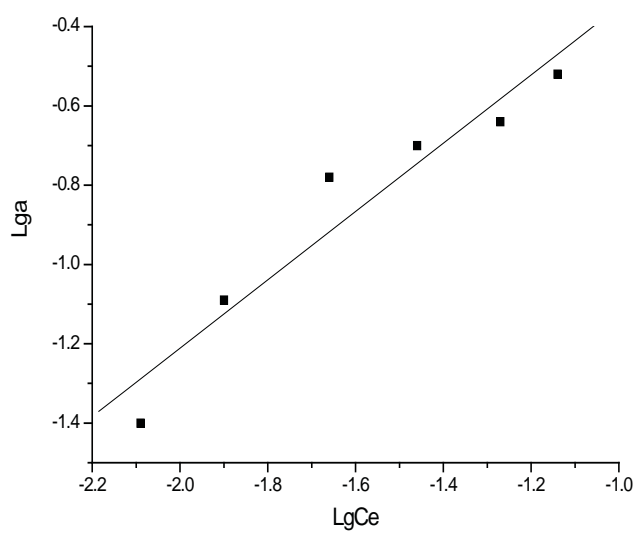

Figure 10. Adsorption isotherm of strontium ions on active carbon CAN-8ox, in coordinates of Freundlich equation.

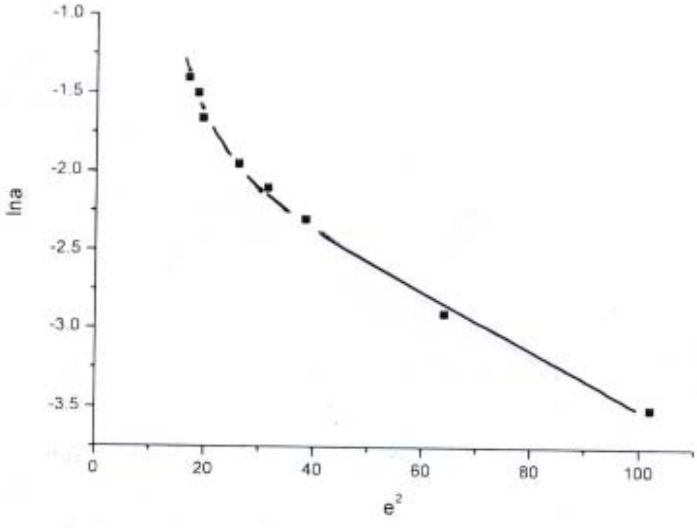

Figure 11. Adsorption isotherm of strontium ions on activated carbon CAN-7, in coordinates of DubininRadushkevich equation ( $e$ - Polanyi potential).

The adsorption isotherm of strontium ions from aqueous solutions on activated carbon CAN-7 in coordinates of Dubinin-Radushkevich equation ( $A$ - differential molar free energy of adsorption, Eq.(2)) is illustrated in Figure 12.

$$
A=R T \ln \left(\frac{C s}{C e}\right)
$$

where $A$ is differential molar free energy of adsorption;

$R$ - gas constant;

$T$ - temperature;

$\mathrm{Ce}$ - equilibrium concentration of strontium ions in solution;

$\mathrm{Cs}$ - water solubility of strontium nitrate.

According to the data reported in Figure 12, Dubinin-Radushkevich equation well describes the process of strontium ions adsorption on activated carbon CAN-7 only over the equilibrium concentrations range of 0.016- $0.084 \mathrm{mmol} / \mathrm{L}$. The deviation of data points from a straight line demonstrates that in the range of equilibrium concentrations $0.084-0.235 \mathrm{mmol} / \mathrm{L}$ adsorption of strontium ions occurs in mesopores and in this concentration range Dubinin-Radushkevich equation can not be applied.

Figure 13 depicts the adsorption isotherm of strontium ions from aqueous solutions on CAN-8ox activated carbon in coordinates of Dubinin-Radushkevich equation. In accordance with the experimental data included in Figure 13, Dubinin-Radushkevich equation well describes the process of strontium ions adsorption on CAN-8ox activated carbon. 


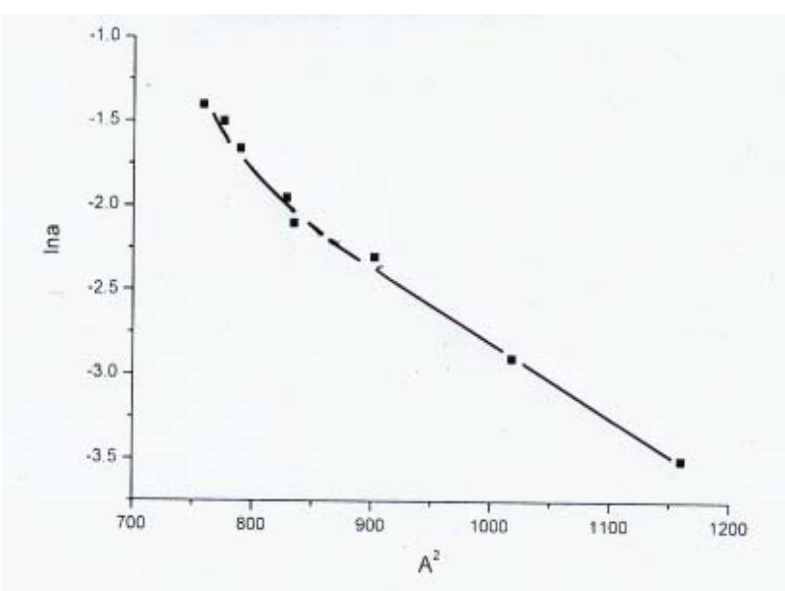

Figure 12. The adsorption isotherm of strontium ions on activated carbon CAN-7 in the coordinates of Dubinin-Radushkevich equation

(A- differential molar free energy of adsorption).

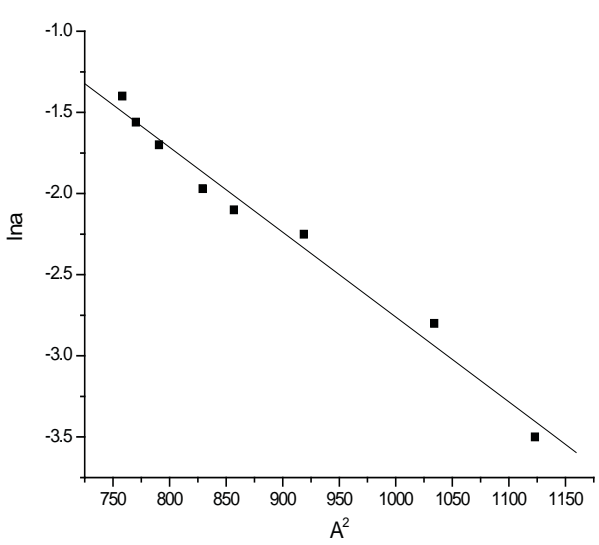

Figure 13. The adsorption isotherm of strontium ions on activated carbon $\mathrm{CAN}-80 \mathrm{x}$ in the coordinates of Dubinin-Radushkevich equation (A-differential molar free energy of adsorption).

Figure 14 shows the isotherm of adsorption of strontium ions on CAN-7 activated carbon from real water, containing in addition to the $\mathrm{Sr}^{2+}$ ions $(9.96 \mathrm{mg} / \mathrm{L})$, also $\mathrm{Ca}^{2+}(37 \mathrm{mg} / \mathrm{L})$ and $\mathrm{Mg}^{2+}(16 \mathrm{mg} / \mathrm{L})$ ions, and pollutants that are often encountered in deep waters.

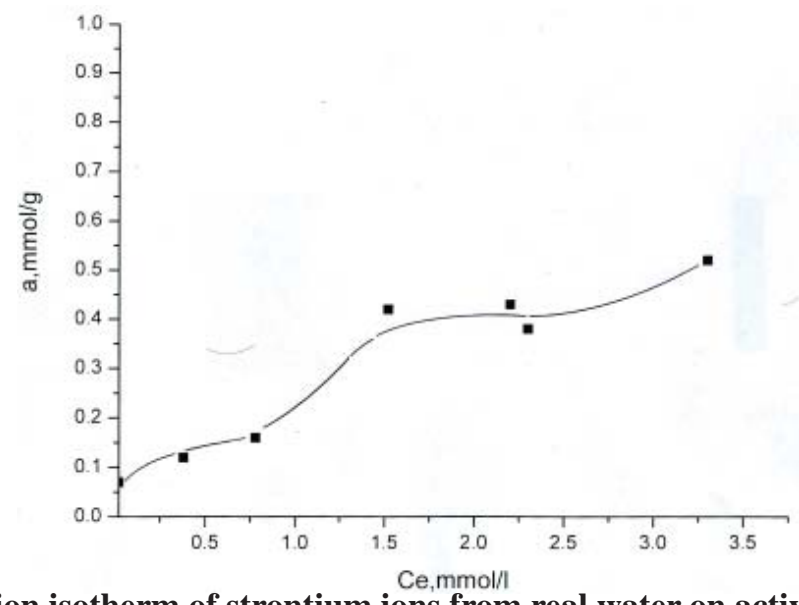

Figure 14. Adsorption isotherm of strontium ions from real water on activated carbon CAN-7.

The presented data reveal that the activated carbons CAN-7 and CAN-8ox can be successfully employed in removing the strontium, calcium and magnesium ions from real water. However, the competitive process of adsorption must be taken into account that is in favour of calcium ions, according to the series of adsorption capacity: $\mathrm{NH}_{4}^{+}<\mathrm{Na}^{+}$ $<\mathrm{Rb}^{+}<\mathrm{Cs}^{+}<\mathrm{Mg}^{2+}<\mathrm{Cd}^{2+}, \mathrm{Mn}^{2+}<\mathrm{Sr}^{2+}<\mathrm{Ca}^{2+}<\mathrm{Zn}^{2+}, \mathrm{Fe}^{2+}<\mathrm{Ni}^{2+}, \mathrm{Al}^{3+}<\mathrm{Y}^{3+} \leq \mathrm{Cr}^{3+} \leq \mathrm{Be}^{2+}<\mathrm{Cu}^{2+}<\mathrm{Fe}^{3+}[15]$. Thus, in order to efficiently remove strontium ions in water by the adsorption method, it must not contain calcium ions at all, or contain their small amount.

\section{Conclusions}

The study of adsorption of strontium ions from aqueous solutions on active carbons CAN-7 and CAN-8ox has demonstrated a similarity in allure of the obtained isotherms: both adsorption isotherms have inflection points.

Dubinin-Radushkevich equation well describes the adsorption of strontium ions from aqueous solutions on active carbons CAN-8ox and CAN-7, in the range of equilibrium concentrations $0.016-0.084 \mathrm{mmol} / \mathrm{L}$.

The process of adsorption of strontium ions from aqueous solutions on activated carbon CAN-7, obtained by chemical activation with orthophosphoric acid, takes place due to the interaction of strontium ions with $\mathrm{P}=\mathrm{O}$ and C-O-P groups, with formation of stable compounds, but also by ion exchange.

From the mixture with substantial amounts of calcium and magnesium ions, adsorption of strontium ions from water decrease in a certain extent, still remaining considerable. 


\section{References}

1. The potential regulatory implications of strontium. American Water Works Association, http://www.awwa.org/ Portals/0/files/legreg/documents/2014AWWAStrontiumBriefingPaper.pdf.

2. The quality control of the sanitary-epidemiological rules and standards of SanPiN 2.1.4.1074-01. Russian Ministry of Health, Russian Federation, Moscow, 2002, 62 p. (in Russian).

3. Ahmadpour, A.; Zabihi, M.; Tahmasbi, M.; Rohani Bastami M.T. Effect of adsorbents and chemical treatments on the removal of strontium from aqueous solutions. Journal of Hazardous Materials, 2010, 182, pp. 552-556.

4. Yakout S.M.; Elsherif, E. Batch kinetics isotherm and thermodynamic studies of adsorption of strontium from aqueous solutions onto low cost rice-straw based carbons. Carbon-Science and Technology, 2010, 1, pp. 144-153.

5. Shawarbkeh, R.A.; Rockstraw, D.A.; Bheda, R.K. Copper and strontium adsorption by a novel carbon material manufactured from pecan shells. Carbon, 2002, 40, pp. 781-786.

6. Cheng, H.N.; Waetelle, L.H.; Klasson, K.T.; Edwards, J.C. Solid-state NMR and ESP studies of activated carbons produced from pecan shells. Carbon, 2010, 48, pp. 2455-2469.

7. Lupascu, T.; Ciobanu, M.; Botan, V.; Nistor, A. Catalytic oxidation of methylene blue. Chemistry Journal of Moldova, 2010, 5(2), pp. 37-40.

8. Shepel, D.; Goreacioc, T.; Lupascu, T.; Filippov, M.; Rusu, M. Method of infrared spectra registration of activated carbons in potassium bromide pellets. Chemistry Journal of Moldova, 2015, 10(1), pp. 113-115.

9. Brunauer, S.; Deming, L.; Deming, W; Teller, E. On the theory of the Van der Waals adsorption of gases. Journal of American Chemical Society, 1940, 62(7), pp. 1723-1732.

10. Dubinin, M.M.; Serpinsky, V.V. On the issue of the equation of adsorption isotherms of water vapors on active charcoal. Reports of the Academy of Science of USSR, 1954, 99(6), pp. 1033-1036 (in Russian).

11. Biniak, S.; Pacula, M.; Szymanski, G.S.; Swiatkowski, A. Effect of activated carbon surface oxygen-and/ or nitrogen-containing groups on adsorption of cooper (ii) ions from aqueous solution. Langmuir, 1999, 15, pp. 6117-6122.

12. Qadeer, R.; Hanif, J.; Hanif, I. Kinetics of strontium ions adsorption on activated charcoal from aqueous solutions. Journal of the Chemical Society of Pakistan, 1995, 17(2), pp. 74-77.

13. Qadeer, R.; Hanif, J.; Saleem, M.; Afzal, M. Selective Adsorption of strontium on activated charcoal from electrolytic aqueous solutions. Collection of Czechoslovak Chemical Communications, 1992, 57(10), pp. 2065-2072.

14. Sveshnikova, D.A.; Gafurov, M.M.; Ataev, M.B.; Rabaldanov, K.Sh.; Asvarov, A.Sh.; Ramazanov, A.Sh.; Kunjueva, K.G. Sorption of rubidium and caesium ions on chemically modified active carbons. Chemistry, Physics and Technology of Surface, 2013, 4(1), pp. 27-36 (in Russian).

15. Tarkovskaja, I.A. Oxidized carbon. Naukova dumka: Kiev, 1981, 197 p. (in Russian).

16. Puzii, A.M.; Poddubnaja, O.I.; Stavitskaja, S.S. Acid-base properties of carbon sorbents determined by potentiometric titration. Russian Journal of Applied Chemistry, 2004, 77(8), pp. 1279-1283 (in Russian).

17. Puzii, A.M. Methods for the preparation, structure and physicochemical properties of phosphorylated carbon adsorbents. Theoretical and Experimental Chemistry, 2011, 47(5), pp. 265-278.

18. Dobrovolski, R.; Jaroniec, M.; Kosmulski M. Study of Cd(II) adsorption from aqueous solution on activated carbon. Carbon, 1986, 24(1), pp. 15-20. 